Article

\title{
Evaluation of the anthelmintic properties of a traditional remedy based on a mixture of red algae using an in vitro assay on gastrointestinal nematodes of donkeys
}

\author{
Michela Maestrini ${ }^{1, *}$, Marcelo Beltrão Molento ${ }^{2}$, Simone Mancini ${ }^{1}$, Francesco Saverio Robustelli della \\ Cuna $^{3}$, Giovanni Furnari ${ }^{4}$, Donatella Serio ${ }^{4}$, Laura Cornara ${ }^{5}$ and Stefania Perrucci ${ }^{1}$ \\ 1 Department of Veterinary Sciences, University of Pisa, Viale delle Piagge 2, 56124 Pisa, Italy. \\ 2 Laboratory of Veterinary Clinical Parasitology, Department of Veterinary Medicine, University of Paraná, R: dos \\ Funcionarios, 1540, Curitiba CEP: 80035-050, PR, Brazil. \\ 3 Department of Drug Sciences, University of Pavia, Viale Taramelli, 627100 Pavia, Italy. \\ 4 Department of Biological, Geological and Environmental Sciences, University of Catania, Via Empedocle 58, 95128 \\ Catania, Italy. \\ 5 Department of Earth, Environment and Life Sciences, University of Genoa, Corso Europa 26, 16132 Genoa, Italy. \\ * Correspondence: michela.maestrini@phd.unipi.it
}

Received: 19 November 2020; Accepted: 21 December 2020; Published: 25 January 2021.

\begin{abstract}
The anthelmintic properties and composition of an Italian traditional anthelmintic remedy based on a red algae mixture (RAE) was assessed using the egg hatch test (EHT). The ability of different dilutions $(1.0,5.0,50$, or $100 \%)$ of RAE was determined and compared with the positive and negative controls against gastrointestinal nematode (GIN) of donkeys. The experiment was performed in triplicate. Data were analysed using the ANOVA and Tukey test. In the mixture, Palisada tenerrima, Laurencia intricata and Laurencia spp. red algae were identified. The $100 \%$ RAE was able to totally inhibit the egg hatch, showing an efficacy comparable $(P<0.05)$ to that of the reference drug $(98.7 \%)$. An egg hatch reduction of $89.5,43.7$, and $23.4 \%$ was observed at 50, 5 and $1 \%$ dilutions, respectively. In conclusion, RAE was able to inhibit the egg hatch of GIN of donkeys in a concentration-dependent manner with a correlation coefficient $(R 2)$ of 0.968 , corroborating with its anthelmintic effect.
\end{abstract}

Keywords: Anthelminthic activity, donkey, gastrointestinal nematodes, red algae, traditional medicine.

\section{Introduction}

T he impact of helminth infections associated with the lack of efficacy of the major commercial compounds and reports of anthelmintic resistant strains worldwide [1,2], has raised the need to find alternative methods for the control of parasites of equids. Moreover, the low probability of obtaining new synthetic anthelmintic drugs [3], and the increasing demand for organically produced food [4], represent additional factors that further increase the need for sustainable methods for parasite control.

More recently, new approaches have been widely studied for the control of equid nematode infections. These include pasture management [5,6], the selection of adapted/rustic and resistant breeds [7], biological control methods [8,9], and the offering of nutraceuticals and other natural therapies [10-12]. The latter are considered particularly promising for the control of gastrointestinal nematodes (GIN) in livestock [10,13]. In fact, natural compounds can be the source of new anthelmintic molecules or can be directly used for the formulation of food supplements [14].

People in most regions, have always used plants and other natural compounds as treatment for various ailments and diseases, including those caused by parasites $[15,16]$. Among the countless natural compounds known for their benefits, marine compounds have also shown a wide range of activities such as anthelmintic, antibacterial, anticoagulant, antifungal, antiprotozoal, and antiviral $[17,18]$. Due to their nutritional value and the content of bioactive molecules, especially marine macroalgae (seaweeds) are often used as food, herbal medicines, and dietary supplements [19]. Seaweeds, comprising thousands of species, are vegetal organisms empirically distinguished in red, brown and green algae belonging to three phyla: Rhodophyta, Ochrophyta and Chlorophyta, respectively. Such phyla, however, differs each other in addition to pigmentation, more substantially in thallus structure, biochemical characteristics including photosynthetic pigments, reproductive 


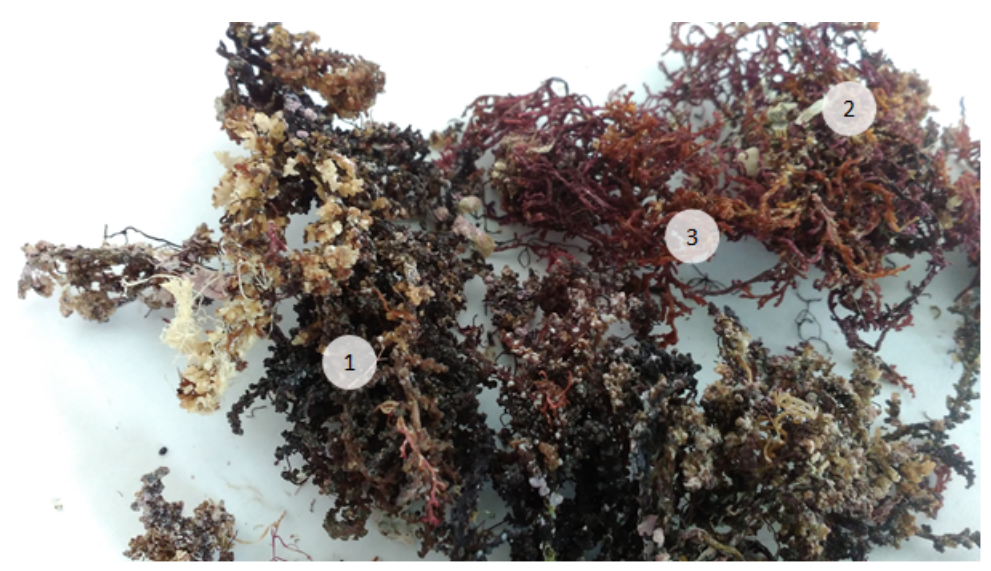

Figure 1. Mixture of the red algae, which includes Palisada tenerrima (1), Laurencia intricata (2), and Laurencia spp. (3), collected on the rocks in the intertidal zone from Favignana island (the Egadi Islands, Sicily, Italy).

structures, ultrastructure of chloroplasts, storage compounds, etcetera. Red algae are known not only for their use in food and cosmetic productions [20], but also for their numerous biological activities, including anticancer [21], antidiarrheal [22], antimicrobial and anthelmintic activities [17,22-24]. The latter activity has been known since ancient times in Eastern countries and around the Mediterranean area including Italy, where red algae were used as an anthelmintic in popular medicine $[25,26]$.

The anthelmintic activity of red algae was previously reported in Italy, such as Ellisolandia elongata (syn. Corallina elongata), taken as decoction in the Tuscany Archipelago [27], and Hypnea musciformis eaten fresh for the same purpose used in the coastal of Abruzzo [25,26]. In Sicily, many species of red algae are also well known for their medicinal property [28]. During an ethnobotanical survey carried out in the Sicilian Egadi Islands, several reports of the anthelmintic use of an aqueous extract (about at 10\%) made with a mixture of red algae gathered on the rocks in intertidal zone, which was called "semenza de vermi", were collected. This aqueous extract was widely used in the past mainly to treat worm infections in children, and it was even marketed out of the islands until the post-war period (Laura Cornara, unpublished data).

Considering the ethnobotanical relevance of this remedy used for the treatment of human worm infections in the Italian folk medicine, this study was aimed to assess in vitro the effective anthelminthic properties of this red algal aqueous extract on donkey nematodes. Another objective was to identify the components of the red algal species that composed the mixture of this remedy. In fact, the confirmation of the anthelminthic properties of this extract could be extremely useful for its possible use as a new tool for the control of nematode infections in donkeys, and possibly be used in other mammals.

\section{Materials and methods}

\subsection{Red algae collection, identification, and extract preparation}

We collected a mixture of red algae on sea rocks in the intertidal zone, following the method used by elderly people from Egadi Islands to prepare anthelmintic remedies. The material was collected at Favignana island, Egadi islands, Sicily, Italy, in January 2017. The algal species in the mixture were identified according to Furnari et al., [29], and Serio et al., [30] description keys (see Figure 1).

From this mixture, a $10 \%$ aqueous extract (red algae extract, RAE) was obtained. For this, $50 \mathrm{~g}$ of dried algae were macerated in $500 \mathrm{ml}$ of distilled water for $3 \mathrm{~h}$, followed by sonication for $30 \mathrm{~min}$. The crude extract was filtered $(0.45 \mu \mathrm{m}$ filter), frozen and lyophilised (yield of $75.6 \%$ on a dry matter basis). The dried extract (10 g) was solubilized in distilled water $(100 \mathrm{ml})$. The obtained solution was frozen until it was used for the in vitro activity tests.

\subsection{Recovery, suspension, and purification of gastrointestinal strongyles (GIN) eggs}

Individual faecal samples were taken from the rectal ampoule of naturally infected donkeys and analysed using a McMaster method with a sensitivity of 50 eggs per gram of faeces (EPG) [31]. Only samples with more than 1000 EPG were pooled and used in the study. A previously reported technique was used for the 
concentration and purification of the GIN eggs [13]. Purified eggs were diluted in saline solution, counted, and used for the in vitro evaluation for the RAE anthelmintic test, using a minimum of 100 eggs in each repetition.

\subsection{Faecal cultures and identification of GIN genera}

The identification of GIN genera was carried out through the setting up of faecal cultures from the same pooled samples used to obtain the eggs. More specifically, about 20 grams of pooled faeces were placed on a gauze stretched inside a plastic cup containing about $20 \mathrm{ml}$ of water and covered with the bottom of a perforated plastic cup to allow proper oxygenation. Faecal cultures were incubated at $26-28^{0} \mathrm{C}$ for 7 days [32]. During the incubation period, faecal cultures were sprayed with water daily, to ensure adequate humidity conditions. After this period, L3 were obtained by using the Baermann technique and were morphologically identified at the genus/species level according to reference keys [32,33].

\subsection{Egg hatch test (EHT)}

The EHT was used to evaluate the in vitro anthelmintic efficacy of the RAE. This test consists in evaluating the ability of a substance to inhibit the hatch of the egg, impeding the development of the L1 [34]. As previously described [13,35], $0.5 \mathrm{ml}$ of saline containing about 100 purified eggs were placed inside each well (24-flat bottom cell plates) (Sarstedt, Verona, Italy), together with $0.5 \mathrm{ml}$ of the $10 \%$ extract at different dilutions $(100,50,5.0,1.0 \%)$ in distilled water. The anthelmintic efficacy of each concentration of the RAE was compared to untreated controls, containing about 100 purified eggs in $0.5 \mathrm{ml}$ of saline $+0.5 \mathrm{ml}$ of distilled water, or treated with $0.5 \mathrm{ml}$ of the reference anthelmintic drug thiabendazole (TBZ) diluted at $1 \%$ in distilled water (Sigma Aldrich, Milan, Italy). All tests were performed in triplicate and in three independent assays. Plates were incubated for $48 \mathrm{~h}$ at $24^{\circ} \mathrm{C}$, in the dark with $90 \%$ relative humidity. After this time, the plates were observed under a Leica M165 C (Leica Microsystems, Milan, Italy) stereoscopic microscope and the number of larvae and eggs present in each plate was counted. The percentage of egg hatch reduction at each concentration was calculated using the following formula [(n. larvae/n. larvae + n. eggs $) \times 100]$ [11].

\subsection{Statistical analysis}

Statistical analysis was performed by using one-way ANOVA with a significance of $5 \%(P<0.05)$. Significant data were further tested with the Tukey post-hoc test. Statistical analysis was carried out by using the Statistical Analysis System (SAS) program.

\section{Results}

In the red algae mixture, Palisada tenerrima, Laurencia intricata and Laurencia spp. were identified (see Figure 1). Moreover, in the collected materials, P. tenerrima, L. intricata and Laurencia spp. were found in the proportion $2: 1.5: 0.5$, respectively.

The pure RAE was able to cause $100 \%$ inhibition of egg hatch, showing an efficacy comparable to TBZ 1\%(98.7\%) (see Figure 2). Furthermore, the anthelmintic efficacy of the extract was found to have a concentration-dependent effect, with an equation of $y=26.35 \times 27.99$ and the correlation coefficient (R2) of 0.968. In fact, at all other dilutions (50,5 and 1\%), the RAE tested in the study showed a decreasing efficacy of $89.5,43.7$, and $23.4 \%$, respectively. Moreover, the two lowest dilutions of the extract showed a significant $(P<0.05)$, lower activity than the pure extract and the reference drug.

The identification of GIN genera from the pooled faecal cultures revealed a high prevalence $(>90 \%)$ of cyathostomins. More specifically, we found species belonging to the genera Cylicocyclus and Cylicostephanus. The remaining $10 \%$ of the identified larvae were identified as Triodontophorus.

\section{Discussion}

We have demonstrated the effect of RAE against GIN eggs of donkeys. Red algae are a group of eukaryotic organisms also known as rhodophytes, most of which live in warm seas [36]. About 4000 different species of red algae have been identified [37]. The alimentary use of red and other algae is particularly widespread in Eastern countries, where they are considered a gastronomic delicacy and a food source with excellent nutritional qualities (i.e. proteins, vitamins) [38,39]. Algae are also used as stabilizers, thickeners, emulsifiers, and gelling agents, and as adjuvants in the treatment of obesity, cellulite, and related diseases $[18,20]$. However, nowadays green, brown, and red marine algae are also considered an important source of 


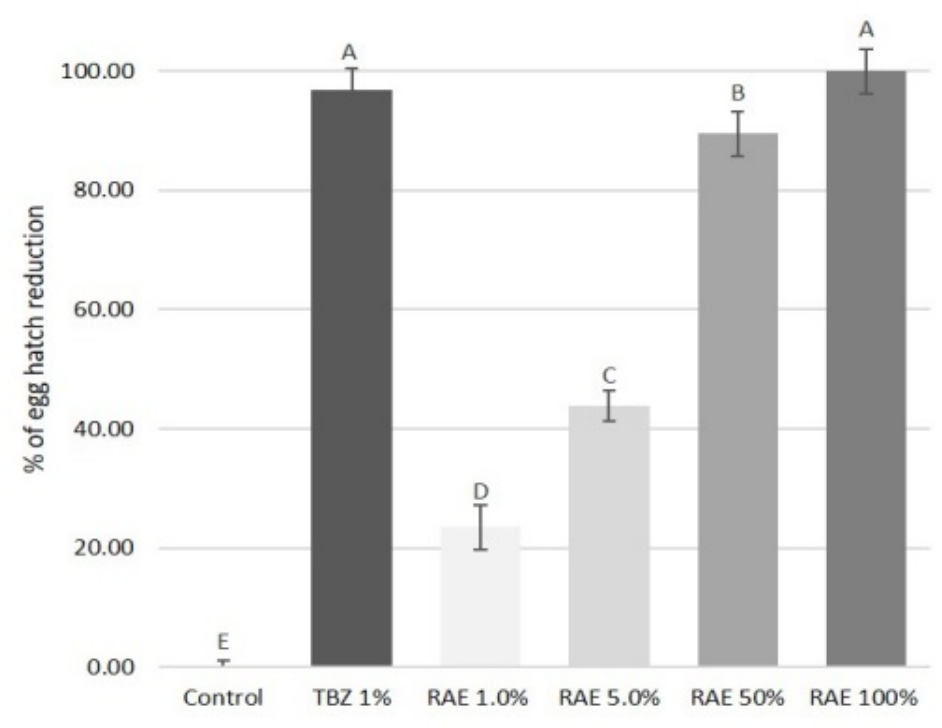

Figure 2. Percentage of egg hatch reduction from 1.0,5.0,50, and $100 \%$ dilutions of the Laurencia intricata, Palisada tenerrima and Laurencia spp. 10\% aqueous extract (RAE) and thiabendazole at 1\% (TBZ 1\%) against gastrointestinal parasites of donkeys.

bioactive compounds that can be used to inhibit pathogens, such as bacteria, viruses, and parasites [17,40-43], including helminth infections $[17,41]$.

Digenea spp. red algae are in fact known for more than a thousand years for their anthelmintic properties against intestinal ascarid worms [44,45]. Kainic acid is considered the active compound responsible for the deworm activity of this group of algae and it is probably due to its ability to induce a neuromuscular paralysis, which interrupts the peristaltic movements of the intestine of the parasites [23]. Kainic acid belongs to the family of kainoids that include also domoic acid, another neurotoxic compound produced mainly by marine planktonic diatom algae [46]. The similar activity of domoic and kainic acids is due to their related structure with glutamic acid, which alters the function of some ion channels [45,47]. At the dose of 5 to $10 \mathrm{mg}$, the domoic and kainic acids can permit the expulsion of roundworms without causing any side-effects in the infected hosts $[23,48]$. Domoic acid may be concentrated in marine seafood, such as oysters, mussels and crustaceans. Sea-food poisoning can be related to domoic acid to fish and humans [49,50]. The ingestion of marine organisms containing high levels of domoic acid, may even cause the death of fish and other marine mammals.

A further major class of metabolites produced by marine algae are represented by terpenes [43]. The Rhodophyceae are characterized by a high content in polyhalogenated monoterpenes showing potent and wide antimicrobial activities [51,52]. In this study, the $10 \%$ aqueous extract from P. tenerrima, L. intricata and Laurencia spp. red algae showed a high anthelmintic efficacy against GIN of donkeys, comparable to that of the reference drug (TBZ 1\%). In addition, the in vitro anthelmintic efficacy showed a concentration-dependent effect against GIN eggs. Even the efficacy of RAE at 50\% was high, with an egg hatch reduction of about $90 \%$.

This is the first study in which the anthelmintic activity of a RAE was tested using the EHT against nematode eggs of GIN of donkeys. It is interesting to note that the anthelmintic properties of algal species of the genus Laurencia were already reported [41,53]. Indeed, among 11 sequiterpenes and a long chain aldehyde from Laurencia dendroidea (syn. Laurencia scoparia), a halogenated $\beta$-bisabolene sesquiterpenoid showed anthelmintic properties against Nippostrongylus brasiliensis [41], a gastrointestinal nematode of rats with a life cycle and morphology similar to the human hookworms [54]. Moreover, very similar results to those obtained in the present study were reported when evaluating the anthelmintic activity against Meloidogyne javanica, an important plant root-knot nematode species. The methanolic and aqueous extracts of several seaweed species were tested using the EHT and the larval mortality test [55]. More specifically, in the previous study, a 10\% aqueous extract of the algal species Sargassum tenerrimum, Padina tetrastromatica and Melanothamnus afaghusainii were able to cause a reduction of about $96 \%$ of the egg hatch of Meloidogyne javanica [55]. However, in the study of Kha et al., [55], the 10\% aqueous extract from the algal species, including Laurencia pinnatifida (now Osmundea pinnatifida), showed a lower anthelmintic activity in the EHT when compared to the $10 \%$ aqueous extract examined in the present study. 
Nevertheless, the phytochemical profile of the RAE tested in this study was not performed, and further studies aimed to identify the different components present in the extract are needed. In fact, the knowledge of the main bioactive components of this aqueous red algal extract could allow to estimate its potential toxic effects to mammals and, therefore, its effective potential as an anthelmintic of seaweed origin. Nevertheless, it is plausible to hypothesize that the anthelmintic activity of the RAE can probably be ascribed to the presence of kainic acid, as reported in other species of red algae [44,45]. Other compounds may also be important (i.e. sesquiterpenoids, 1-aminocyclopropane-1-carboxylic, and acrylic acids) to red algae, which in previous studies were found to possess anthelmintic properties [53,55].

Further studies are needed to evaluate the anthelmintic activity of each of the three algal species contained in the mix of algae tested in this study. In fact, these latter studies may permit to assess whether there is a synergism among these species, or if one species has higher activity than the others. Finally, although in previous studies nematodes have been found to be highly tolerant to salinity [56,57], the potential anthelmintic effects of the content in sodium chloride of the tested algal extract cannot be excluded.

In conclusion, results from this study seem to confirm the anthelmintic properties previously reported in the Italian folk medicine for the red algae extract. Further studies based on the bio-guided purification of the red algae extract are encouraged.

Acknowledgments: Authors thank Egadi islands (Sicily, Italy) informants and in particular Mr. Santo Grammatico, for their help in collecting red algae. Authors thank Dr. Elena Hobart for her kind help in revising the English language.

Author Contributions: Conceptualization (LC, SP, MM); red algae collection (LC); red algae identification (GF and DS); extract preparation (FSRC); experimental (MM, MBM, SP); data analysis (SM, MM); writing the original draft (MM, SP). All authors revised and edited the final version of the manuscript.

Conflicts of Interest: "The Authors declare that there is no conflict of interest."

\section{References}

[1] Canever, R. J., Braga, P. R., Boeckh, A., Grycajuck, M., Bier, D., \& Molento, M. B. (2013). Lack of Cyathostomin sp. reduction after anthelmintic treatment in horses in Brazil. Veterinary Parasitology, 194(1), 35-39.

[2] Sangster, N. C., Cowling, A., \& Woodgate, R. G. (2018). Ten events that defined anthelmintic resistance research. Trends in Parasitology, 34(7), 553-563.

[3] Stratford, C. H., McGorum, B. C., Pickles, K. J., \& Matthews, J. B. (2011). An update on cyathostomins: anthelmintic resistance and diagnostic tools. Equine Veterinary Journal, 43, 133-139.

[4] Hoste, H., \& Torres-Acosta, J. F. J. (2011). Non chemical control of helminths in ruminants: adapting solutions for changing worms in a changing world. Veterinary Parasitology, 180(1-2), 144-154.

[5] Hernández, J. Á., Sánchez-Andrade, R., Cazapal-Monteiro, C. F., Arroyo, F. L., Sanchís, J. M., Paz-Silva, A., \& Arias, M. S. (2018). A combined effort to avoid strongyle infection in horses in an oceanic climate region: rotational grazing and parasiticidal fungi. Parasites \& Vectors, 11(1), 240.

[6] Pellegrini, L. G. D., de Pellegrin, A. C. R., Monteiro, A. L. G., Molento, M. B., Neumann, M., \& Longhi, E. (2011). Parasitic infection of lambs and larval contamination in pasture submitted to nitrogen fertilization. Pesquisa Veterinária Brasileira, 31(12), 1097-1101.

[7] Aguerre, S., Jacquiet, P., Brodier, H., Bournazel, J. P., Grisez, C., Prévot, F., ... \& Moreno, C. R. (2018). Resistance to gastrointestinal nematodes in dairy sheep: genetic variability and relevance of artificial infection of nucleus rams to select for resistant ewes on farms. Veterinary Parasitology, 256, 16-23.

[8] Buzatti, A., de Paula Santos, C., Fernandes, M. A. M., Yoshitani, U. Y., Sprenger, L. K., dos Santos, C. D., \& Molento, M. B. (2015). Duddingtonia flagrans in the control of gastrointestinal nematodes of horses. Experimental Parasitology, $159,1-4$.

[9] Degenkolb, T., \& Vilcinskas, A. (2016). Metabolites from nematophagous fungi and nematicidal natural products from fungi as alternatives for biological control. Part II: metabolites from nematophagous basidiomycetes and non-nematophagous fungi. Applied Microbiology and Biotechnology, 100(9), 3813-3824.

[10] Giovanelli, F., Mattellini, M., Fichi, G., Flamini, G., \& Perrucci, S. (2018). In vitro anthelmintic activity of four plant-derived compounds against sheep gastrointestinal nematodes. Veterinary Sciences, 5(3), Artilce no. 78.

[11] Peachey, L. E., Pinchbeck, G. L., Matthews, J. B., Burden, F. A., Mulugeta, G., Scantlebury, C. E., \& Hodgkinson, J. E. (2015). An evidence-based approach to the evaluation of ethnoveterinary medicines against strongyle nematodes of equids. Veterinary Parasitology, 210(1-2), 40-52.

[12] Santos, C., Campestrini, L. H., Vieira, D. L., Pritsch, I., Yamassaki, F. T., Zawadzki-Baggio, S. F., ... \& Molento, M. B. (2018). Chemical Characterization of Opuntia ficus-indica (L.) Mill. Hydroalcoholic Extract and Its Efficiency against Gastrointestinal Nematodes of Sheep. Veterinary Sciences, 5(3), Article No. 80. 
[13] Maestrini, M., Tava, A., Mancini, S., Tedesco, D., \& Perrucci, S. (2020). In vitro anthelmintic activity of saponins from Medicago spp. against sheep gastrointestinal nematodes. Molecules, 25(2), Article No. 242.

[14] Chaaban, A., Gomes, E. N., Richardi, V. S., Martins, C. E. N., Brum, J. S., Navarro-Silva, M. A., ... \& Molento, M. B. (2019). Essential oil from Curcuma longa leaves: Can an overlooked by-product from turmeric industry be effective for myiasis control?. Industrial Crops and Products, 132, 352-364.

[15] Huffman, M. A. (2003). Animal self-medication and ethno-medicine: exploration and exploitation of the medicinal properties of plants. Proceedings of the Nutrition Society, 62(2), 371-381.

[16] Romero-Benavides, J. C., Ruano, A. L., Silva-Rivas, R., Castillo-Veintimilla, P., Vivanco-Jaramillo, S., \& Bailon-Moscoso, N. (2017). Medicinal plants used as anthelmintics: Ethnomedical, pharmacological, and phytochemical studies. European Journal of Medicinal Chemistry, 129, 209-217.

[17] Mayer, A. M., Rodríguez, A. D., Berlinck, R. G., \& Hamann, M. T. (2009). Marine pharmacology in 2005-6: Marine compounds with anthelmintic, antibacterial, anticoagulant, antifungal, anti-inflammatory, antimalarial, antiprotozoal, antituberculosis, and antiviral activities; affecting the cardiovascular, immune and nervous systems, and other miscellaneous mechanisms of action. Biochimica et Biophysica Acta (BBA)-General Subjects, 1790(5), $283-308$.

[18] Petrocelli, A., \& Cecere, E. (2019). A 20-year update on the state of seaweed resources in Italy. Botanica Marina, 62, 249-264.

[19] Corino, C., Modina, S. C., Di Giancamillo, A., Chiapparini, S., \& Rossi, R. (2019). Seaweeds in pig nutrition. Animals, 9(12), 1126.

[20] Smit, A. J. (2004). Medicinal and pharmaceutical uses of seaweed natural products: a review. Journal of Applied Phycology, 16(4), 245-262.

[21] Sajadimajd, S., Momtaz, S., Haratipour, P., El-Senduny, F. F., Panah, A. I., Navabi, J., ... \& Rahimi, R. (2019). Molecular mechanisms underlying cancer preventive and therapeutic potential of algal polysaccharides. Current Pharmaceutical Design, 25(11), 1210-1235.

[22] Vo, T. S., Ngo, D. H., Van Ta, Q., \& Kim, S. K. (2011). Marine organisms as a therapeutic source against herpes simplex virus infection. European Journal of Pharmaceutical Sciences, 44(1-2), 11-20.

[23] Stein, J. R., \& Borden, C. A. (1984). Causative and beneficial algae in human disease conditions: a review. Phycologia, 23(4), 485-501.

[24] Vitale, F., Genovese, G., Bruno, F., Castelli, G., Piazza, M., Migliazzo, A., ... \& Morabito, M. (2015). Effectiveness of red alga Asparagopsis taxiformis extracts against Leishmania infantum. Open Life Sciences, 10, 490-496.

[25] Idolo, M., Motti, R., \& Mazzoleni, S. (2010). Ethnobotanical and phytomedicinal knowledge in a long-history protected area, the Abruzzo, Lazio and Molise National Park (Italian Apennines). Journal of Ethnopharmacology, 127(2), 379-395.

[26] Tammaro, F. (1984). Flora officinale d'Abruzzo. A cura del Centro servizi culturali.

[27] Manganelli, R. U., \& Tomei, P. E. (1999). Ethnopharmacobotanical studies of the Tuscan Archipelago. Journal of Ethnopharmacology, 65(3), 181-202.

[28] Barbagallo, C. (1979). Alghe marine della Sicilia orientale di interesse officinale. Scuola Salesiana del Libro.

[29] Furnari, G., Cormaci, M., \& Serio, D. (2001). The Laurencia complex (Rhodophyta, Rhodomelaceae) in the Mediterranean Sea: an overview. Cryptogamie Algologie, 22(4), 331-373.

[30] Serio, D., Cormaci, M., Furnari, G., \& Boisset, F. (2010). First record of Palisada maris-rubri (Ceramiales, Rhodophyta) from the Mediterranean Sea along with three proposed transfers to the genus Palisada. Phycological Research, 58(1), 9-16.

[31] Taylor, M. A., Coop, R. L., \& Wall, R. L. (2007). Parasites of the respiratory system. In. Veterinary Parasitology. 3rd ed., Blackwell Publishing Ltd., Oxford, UK, 195-199.

[32] Ministry of Agriculture, Fisheries and Food (MAFF). (1986). Manual of Veterinary Parasitological Laboratory Techniques; Her Majesty's Stationary Office (HMSO): London, UK, 1986; pp. 1-152.

[33] Bevilaqua, C. M. L., Rodrigues, M. D. L., \& Concordet, D. (1993). Identification of infective larvae of some common nematode strongylids of horses [Strongylus vulgaris, S. equinus, S. edentatus, Triodontophorus spp., Poteriostomum spp., Gyalocephalus capitatus, Cylicocyclus radiatus, C. nassatus, C. minutus, C. poculatus]. Revue de Medecine Veterinaire (France).

[34] Coles, G. C., Jackson, F., Pomroy, W. E., Prichard, R. K., von Samson-Himmelstjerna, G., Silvestre, A., ... \& Vercruysse, J. (2006). The detection of anthelmintic resistance in nematodes of veterinary importance. Veterinary Parasitology, 136(3-4), 167-185.

[35] Maestrini, M., Tava, A., Mancini, S., Salari, F., \& Perrucci, S. (2019). In vitro anthelmintic activity of saponins derived from Medicago spp. plants against donkey gastrointestinal nematodes. Veterinary Sciences, 6(2), Article No. 35.

[36] Díaz-Tapia, P., Maggs, C. A., Macaya, E. C., \& Verbruggen, H. (2018). Widely distributed red algae often represent hidden introductions, complexes of cryptic species or species with strong phylogeographic structure. Journal of Phycology, 54(6), 829-839. 
[37] Gabrielson, P. W., Hughey, J. R., \& Diaz-Pulido, G. (2018). Genomics reveals abundant speciation in the coral reef building alga Porolithon onkodes (Corallinales, Rhodophyta). Journal of Phycology, 54(4), 429-434.

[38] Wells, M. L., Potin, P., Craigie, J. S., Raven, J. A., Merchant, S. S., Helliwell, K. E., ... \& Brawley, S. H. (2017). Algae as nutritional and functional food sources: revisiting our understanding. Journal of Applied Phycology, 29(2), 949-982.

[39] Jørgensen, K., \& Olesen, P. T. (2018). Kainic acid in the seaweed Palmaria palmata (dulse). Food Additives $\mathcal{E}$ Contaminants: Part B, 11(3), 198-200.

[40] Koishi, A. C., Zanello, P. R., Bianco, É. M., Bordignon, J., \& dos Santos, C. N. D. (2012). Screening of Dengue virus antiviral activity of marine seaweeds by an in situ enzyme-linked immunosorbent assay. PLoS One, 7(12), Article ID: e51089.

[41] Davyt, D., Fernandez, R., Suescun, L., Mombrú, A. W., Saldana, J., Domínguez, L., ... \& Manta, E. (2001). New Sesquiterpene Derivatives from the Red Alga Laurencia scoparia. Isolation, Structure Determination, and Anthelmintic Activity. Journal of Natural Products, 64(12), 1552-1555.

[42] Lopes, D., Melo, T., Meneses, J., Abreu, M. H., Pereira, R., Domingues, P., .. \& Domingues, M. R. (2019). A new look for the red macroalga Palmaria palmata: A seafood with polar lipids rich in EPA and with antioxidant properties. Marine Drugs, 17(9), Article No. 533.

[43] Pérez, M. J., Falqué, E., \& Domínguez, H. (2016). Antimicrobial action of compounds from marine seaweed. Marine Drugs, 14(3), Article No. 52.

[44] Hoppe, H. A. (1979). Marine algae and their products and constituents in pharmacy. Marine algae in pharmaceutical science, editors, Heinz A. Hoppe, Tore Levring, Yukio Tanaka.

[45] Jiang, S., Kuwano, K., Nishihara, G. N., Urata, C., Shimoda, R., Takatani, T., \& Arakawa, O. (2018). Uptake of nitrogen and production of kainic acid by laboratory culture of the red alga Digenea simplex. Phycological Research, 66(1), 68-75.

[46] Maeno, Y., Terada, R., Kotaki, Y., Cho, Y., Konoki, K., \& Yotsu-Yamashita, M. (2019). Possible biosynthetic products and metabolites of kainic acid from the red alga Digenea simplex and their biological activity. Journal of Natural Products, 82(6), 1627-1633.

[47] Clayden, J., Read, B., \& Hebditch, K. R. (2005). Chemistry of domoic acid, isodomoic acids, and their analogues. Tetrahedron, 24(61), 5713-5724.

[48] Simoons, F. J. (2014). Food in China: a cultural and historical inquiry. CRC Press. Boca Raton, Florida, USA.

[49] Bates, S.S., Bird, C.J., Freitas, A.S.W.D., Foxall, R., Gilgan, M., Hanic, L.A., Johnson, G.R., McCulloch, A.W., Odense, P., Pocklington, R., Quilliam, M.A., Sim, P.G., Smith, J.C., Rao, D.V.S., Todd, E.C.D., Walter, J.A. and Wright, J.L.C. (1989). Pennate diatom Nitzschia pungens as the primary source of domoic acid, a toxin in shellfish from Eastern Prince Edward Island, Canada. Canadian Journal of Fisheries and Aquatic Sciences, 46, 1203-1215.

[50] Jin, H., Lian, L., Zhou, H., Yan, S., \& Song, W. (2018). Mechanistic consideration of the photochemical transformation of domoic acid (algal toxin) in DOM-Rich brackish water. Chemosphere, 209, 328-337.

[51] Bedoux, G., Hardouin, K., Burlot, A. S., \& Bourgougnon, N. (2014). Bioactive components from seaweeds: Cosmetic applications and future development. In Advances in Botanical Research (Vol. 71, pp. 345-378). Academic Press.

[52] El Gamal, A. A. (2010). Biological importance of marine algae. Saudi Pharmaceutical Journal, 18(1), 1-25.

[53] Lever, J., Brkljaca, R., Kraft, G., \& Urban, S. (2020). Natural Products of Marine Macroalgae from South Eastern Australia, with Emphasis on the Port Phillip Bay and Heads Regions of Victoria. Marine Drugs, 18(3), Article No. 142.

[54] Bouchery, T., Filbey, K., Shepherd, A., Chandler, J., Patel, D., Schmidt, A., ... \& LeGros, G. (2018). A novel blood-feeding detoxification pathway in Nippostrongylus brasiliensis L3 reveals a potential checkpoint for arresting hookworm development. PLoS Pathogens, 14(3), Article ID: e1006931.

[55] Khan, S. A., Abid, M., \& Hussain, F. (2015). Nematicidal activity of seaweeds against Meloidogyne javanica. Pakistan Journal of Nematology, 33(2), 195-203.

[56] Kirk, R. S., Kennedy, C. R., \& Lewis, J. W. (2000). Effect of salinity on hatching, survival and infectivity of Anguillicola crassus (Nematoda: Dracunculoidea) larvae. Diseases of Aquatic Organisms, 40(3), 211-218.

[57] Khanna, N., Cressman Iii, C. P., Tatara, C. P., \& Williams, P. L. (1997). Tolerance of the nematode Caenorhabditis elegans to $\mathrm{pH}$, salinity, and hardness in aquatic media. Archives of Environmental Contamination and Toxicology, 32(1), 110-114. 